\title{
Cochlear blood flow increases after systemic hemodilution: Comparison of simultaneous laser Doppler flowmetry and radioactive microsphere measurements
}

\author{
Alfred L. Nuttall ${ }^{1}$, Elisabeth Hultcrantz ${ }^{2}$, Hans-Christian Larsen ${ }^{2}$ \\ and Clarence Angelborg ${ }^{2}$ \\ ${ }^{I}$ Kresge Hearing Research Institute, Department of Otolaryngology - Head and Neck Surgery, Medical School, The University \\ of Michigan, Ann Arbor, Michigan, U.S.A.; ${ }^{2}$ Department of Otorhinolaryngology, University Hospital, Uppsala, Sweden
}

(Received 19 October 1987; accepted 22 March 1988)

\begin{abstract}
Guinea pig cochlear blood flow was measured before and after systemic normovolemic hemodilution with high molecular weight dextran. Absolute determinations of blood flow (in the cochlea, brain, kidney and lung) were accomplished by use of radioactivelabeled $\left({ }^{85} \mathrm{Sr}\right.$ or $\left.{ }^{141} \mathrm{Ce}\right)$ microspheres. Relative measurements of the cochlear blood flow changes were made simultaneously by the use of a laser Doppler flowmeter. The flowmeter probe was placed on the first cochlear turn. Hemodilution to an average systemic hematocrit of $20 \%$ increased cochlear blood flow by $250 \%$ as measured with microspheres. The laser Doppler instrument significantly underestimated the actual flow increase giving an indication of $148 \%$. Furthermore, the data, when analyzed on an individual trial basis, showed a very poor correlation between the two methods. The theoretical basis for these findings in relation to the use of the laser Doppler instrument is discussed.
\end{abstract}

Cochlear blood flow; Laser Doppler flowmetry; Radioactive microsphere; Hemodilution; Dextran; Guinea pig

\section{Introduction}

Inner ear blood vessels, hidden in the temporal bone and supplied by an arterial system originating from inside the skull, are difficult to evaluate for their normal function or pathological changes. Consequently, a wide variety of techniques are used to study the inner ear vasculature. Methods that have provided important results include: histological (e.g., Axelsson, 1968; Hawkins, 1971; Ross, 1971; Hawkins et al., 1972; Spoendlin, 1976; Vertes and Axelsson, 1979); intravital microscopy (e.g., Weille et al., 1954; Perlman and Kimura, 1955; Costa and Branemark, 1970; Lawrence, 1970; Nuttall, 1987); electric-impedance plethys-

Correspondence to: A.L. Nuttall, Kresge Hearing Research Institute, The University of Michigan Medical School, $1301 \mathrm{E}$. Ann Street, Ann Arbor, MI 48109-0506, U.S.A. mography (Morimitsu, 1960; Suga and Snow, 1969a,b); and hydrogen clearance (Maass and Kellner, 1984). Indirect evaluations of the cochlear blood flow have also been accomplished by means of measurement of perilymph-production (Schneider, 1974), oxygen tension in perilymph or endolymph (Misrahy et al., 1958; Lawrence and Nuttall, 1972; Maass et al., 1976), and by intracellular trapping of 2-deoxyglucose (Canlon and Schacht, 1983; Ryan et al., 1984).

A quantitative technique of measuring the cochlear blood flow became established when the radioactively-labeled microsphere method was adopted by Angelborg et al., (1977). Normal cochlear blood flow was determined to be about $1-2 \mu 1 / \mathrm{min} /$ cochlea in the guinea pig and somewhat higher in larger animals (Hultcrantz and Angelborg, 1978; Hultcrantz, 1979). With the microsphere method it is possible to make two measurements of blood flow within a short time period 
(using differently labeled spheres) and study the effect of an experimental manipulation. Combined with 'surface-preparation' histology, the microsphere method can also provide information on regional blood flow in the cochlea (Axelsson et al., 1983; Prazma et al., 1984; Angelborg et al., 1985; Larsen et al., 1984; Slepecky et al., 1984, 1987). In practice, however, the microsphere method is difficult to use for organs receiving only a small portion of the cardiac output (such as the cochlea); the inability to record continuous changes is another serious drawback.

The most recent technique which has been adopted to measure cochlear blood flow is laser Doppler flowmetry (Miller et al., 1983, 1984; Goodwin et al., 1984; Hultcrantz et al., 1985). With this technique it is possible to continuously record cochlear blood flux, but additional studies are needed to determine the relationship of the laser Doppler flowmeter readings to actual blood flow in the effective tissue volume measured by the instrument.

A previous report (Hultcrantz and Nuttall, 1987) showed that laser Doppler measured cochlear blood flow was significantly increased by systemic hemodilution with dextrans. The purpose of the present investigation was to measure the actual whole cochlear blood flow change during hemodilution using the microsphere method and directly compare these values with simultaneous laser Doppler flow measurements. We show that both methods indicate greatly increased cochlear blood flow during normovolemic hemodilution but that the laser Doppler flowmeter, for theoretical reasons, gives a reading that is smaller in magnitude and more difficult to interpret. The preliminary results of this study have been presented (Nuttall et al., 1987).

\section{Methods}

Twenty-two pigmented male guinea pigs weighing between 225 and $350 \mathrm{~g}$ were used for this study and 14 animals yielded data for analysis. Anesthesia was induced by diazepam $(5 \mathrm{mg} / \mathrm{kg}$ bwt ip) followed $15 \mathrm{~min}$ later by fentanyl $(0.32$ $\mathrm{mg} / \mathrm{kg}$ bwt $\mathrm{im})$. Occasionally Saffan $(5 \mathrm{mg} / \mathrm{kg}$ bwt im) was given to help induce anesthesia (in 6 of the 14 successful experiments). Maintenance of anesthesia was accomplished by administration of fentanyl $(0.32 \mathrm{mg} / \mathrm{kg}$-bwt $/ \mathrm{hr})$ into the right jugular vein by pump infusion.

The animals were tracheotomized and artificially ventilated with oxygen-enriched air. Arterial blood gas levels were determined (Radiometer Copenhagen PHN) three times during the experiment by drawing $0.25 \mathrm{ml}$ samples from the left common carotid artery or from the left ventricle of the heart (after heart puncture). Rectally-measured body temperature was maintained at $38 \pm$ $1^{\circ} \mathrm{C}$ by a heating blanket. Heart rate was continuously monitored.

The right common carotid artery was cannulated for the measurement of systemic blood pressure. The output of the blood pressure transducer (Statham P37) was recorded on a strip chart recorder simultaneously with the output signal from the laser Doppler instrumentation (Perimed Periflux PF-2). The right femoral artery was cannulated to obtain the reference blood sample for microsphere blood flow determinations. Reference samples were obtained by free flow in 8 early experiments [the technique of Bill and Linder (1976) and Hultcrantz et al. (1977)]. Four of these were successful experiments and were included in the 14 analyzed animals. However, because of observed variability in the free flow rate from the femoral artery, subsequent experiments used a peristaltic roller-type pump (LBK model 10201) which withdrew blood at the constant rate of 0.29 $\mathrm{ml} / \mathrm{min}$ (Angelborg et al., 1977). In order to insure that the sample was obtained at a constant rate, a second pressure transducer monitored the pressure in the femoral catheter. A blocked catheter would result in low or negative pressures during suction.

The reference sample was collected into a reservoir that was large enough to hold both the first and second samples which were allowed to mix. Saline outflow, discharged from the reference sample pump, was collected into a container and weighed as an additional verification of constant withdrawal rate.

A heated metal headholder [to reduce cooling of the head, Brown et al., (1983)] fixed and oriented the head allowing a conventional ventral-approach surgical opening of the middle-ear. The periosteum over the cochlea was removed by wip- 
ing with a cotton pledget. A $1.5 \mathrm{~mm}$ diameter probe of the Perimed Periflux laser Doppler blood perfusion monitor was held in a micromanipulator and positioned to the first cochlear turn over the stria vascularis of the left ear. The flowmeter was always used with a gain setting of 30 , a time constant of $3 \mathrm{~s}$ and an analysis bandwidth of 12 $\mathrm{kHz}$. The gain was sufficient to provide a midrange reading on this instrument and a $3 \mathrm{~s}$ time constant adequately smoothed noise in the signal. A $12 \mathrm{kHz}$ band width was used as the lower bandwidth setting $(4 \mathrm{kHz})$ yielded smaller flow readings indicating that significant levels of Doppler shifted light existed above $4 \mathrm{kHz}$.

The animals were given Pavulon (pancuron bromide, $0.12 \mathrm{mg} / \mathrm{kg} \mathrm{im}$ ) to eliminate body movement artifacts before the left ventricle of the heart was needle-punctured ( $23 \mathrm{~g}$ needle connected to a catheter) through the intact chest wall. The animals were then heparinized with $0.2 \mathrm{ml}$ of heparin in saline ( 5000 USP units $/ \mathrm{ml}$ ) in order to ensure that the injection and withdrawal catheters remained patent. Any potential changes in blood flow as a result of heparinization were well stabilized before the protocol was started.

The experimental protocol was first to obtain arterial blood gases and hematocrit values from a $0.25 \mathrm{ml}$ sample of blood removed from the heart. After a $5 \mathrm{~min}$ period of stable blood pressure, the first microsphere injection was made. Before injection the microspheres were sonicated and suspended in $0.3 \mathrm{ml}$ of warmed physiological saline, which was then thoroughly mixed with $0.1 \mathrm{ml}$ of whole blood drawn from the heart catheter. Injection of this $0.4 \mathrm{ml}$ mixture was made at a constant rate over a $15 \mathrm{~s}$ interval. The reference sample withdrawal was started $15 \mathrm{~s}$ before the $15 \mathrm{~s}$ microsphere injection started and continued for $1 \mathrm{~min}$ following the injection (a total withdrawal time of $90 \mathrm{~s})$.

After a stabilization period of $5 \mathrm{~min}$, normovolemic hemodilution was accomplished by injection of $5 \mathrm{ml}$ of Dextran 75 solution into the jugular vein $(6 \%$ Dextran 75 in physiological saline; Macrodex-Pharmacia $\mathrm{AB}$ ). The injection rate was approximately $1 \mathrm{ml} / \mathrm{min}$. Although this rate is greater than the usual capacity of this vein, it is only 1-2\% of the cardiac output and the blood pressure stability showed that it was well tolerated.
Simultaneously $5 \mathrm{ml}$ of whole blood was removed $(1 \mathrm{ml} / \mathrm{min}$ ) from the animal using the heart needle catheter. This procedure resulted in a gradual hemodilution without significant blood pressure alteration. It should be noted that the low systemic blood pressure of these guinea pigs is consistent with the unusually low blood pressure found in these rodents (Brown et al., 1988).

Following another $5 \mathrm{~min}$ stabilization period, arterial blood gases and hematocrit were determined and the second injection of microspheres was given (using the same injection time and volume parameters). Immediately after the second microsphere injection, the animal was killed by cardiac injection of about $2 \mathrm{ml}$ of $3 \mathrm{M} \mathrm{KCl}$.

In this study, the microspheres used were labeled with ${ }^{85} \mathrm{Sr}(8.97 \pm 0.59 \mu \mathrm{m}$ diameter $)$ and ${ }^{141} \mathrm{Ce}(8.77 \pm 0.38 \mu \mathrm{m}$ diameter $)$ obtained from the 3M Company. Each injection of microsphere mixture ( $0.4 \mathrm{ml}$ of mixed blood and saline) contained about 3 million spheres. The manufacturer supplied the stock microsphere solution with a small amount of Tween to disperse aggregations.

The cochleas were removed from the head and fixed in phosphate buffered glutaraldehyde by gentle perfusion through the round and oval windows. They were stored in the fixative, under refrigeration, along with the reference blood sample; other tissue organ samples were frozen, unfixed. The cochleas were dissected as described by Angelborg et al. (1977) to obtain the membranous labyrinth and modiolus for analysis. After dissection, the inner ear specimens, the right brain hemisphere, a lung lobe, and wedge sections (center one third) from the right and left kidneys were weighed and analyzed for radioactivity in a gamma-spectrometer (Tracer Analytic, Searle Nuclear, Chicago, IL). Blood and tissue samples were also weighed and counted as well.

Blood flow was calculated according to Equation 1.

$F_{\text {organ }}=A_{\text {organ }} \times F_{\text {ref }} / A_{\text {ref }}$

$F_{\text {organ }}$ is the blood flow of the organ $(\mu \mathrm{g} / \mathrm{min} /$ cochlea or $\mu \mathrm{g} / \mathrm{min} / 100$ gram-tissue), $A_{\text {organ }}$ is the activity of the organ or tissue sample, $F_{\text {ref }}$ is the reference blood flow, and $A_{\text {ref }}$ is the activity in the reference blood sample. 


\section{Results}

Table 1 gives systemic physiological variables for the analyzed animals of this study. The experimental procedures were tolerated well as indicated by the relatively unchanged blood gases, $\mathrm{pH}$, and blood pressure measures. On the average, the normovolemic hemodilution reduced systemic hematocrit to 20\%. These results (and below) are for 14 animals, 10 of which had reference blood samples withdrawn by pump from the right femoral artery while in the remaining 4 animals a free flow technique was used. Eight other guinea pigs were excluded from the analysis, generally because of a failure to acquire an adequate reference sample and in one instance because of middle ear infection.

Fig. 1 shows an example of the blood pressure and laser Doppler flow readings that were obtained before, during and following hemodilution. The injection of microspheres often caused a transient decline in blood pressure which recovered to baseline value after one or two minutes. This transient decrease in pressure was also usually evident in the flowmeter output as a transient decline and recovery. Since these events occurred during the time period that microspheres were being trapped in tissues, the laser Doppler readings used as the initial or final flow values of this study were calculated by graphical integration. The segment of recorded tracing used for the integration period was $30 \mathrm{~s}$ in length beginning at the start of the injection. Following the first microsphere injection the laser Doppler output often demonstrated a secondary transient change, in this case an increase with a slower time-course followed by partial recovery to baseline. Fig. 2 gives an example of this transient increase. Often the recovery level (at $5 \mathrm{~min}$ post injection) was slightly elevated. The transient increase was not part of the measurement period and was allowed to stabilize before hemodilution*.

Blood flow measurements determined by the microsphere method are given in Table 2. This table reveals that the blood flow to right and left organs (the cochleas or kidneys) is similar. A paired $t$-test comparing the blood flow in the right and left cochleas or comparing flow in the right and left kidneys, before and after hemodilution, indicated no significant difference. This should be the case if the microspheres are distributed homogeneously for both injections.

The increase in blood flow to each organ after hemodilution, expressed as a percentage value, is also given in Table 2. A repeated-measures analysis of variance (for 9 guinea pigs) showed that there is a significant difference $(P<0.005)$, among the organs. However, increases seen for the brain and right and left cochlear blood flow were alike $(P>0.86)$.

\footnotetext{
* Subsequent to these experiments, another group of guinea pigs were tested (using non-radioactive microspheres $9.03 \pm$ $1.33 \mu \mathrm{m}$ ) and found less susceptible to the physiological effects which cause the transient blood pressure decline. These later experiments indicate that the secondary increasc in laser Doppler flow readings may be an autoregulatory response to the blood pressure decrease. Similar transient changes were observed at the onset or offset of positive end expiratory pressure (PEEP). PEEP decreases systemic blood pressure in part by reducing cardiac return. The time course of the laser Doppler flow increase seen as a result of microsphere injection could be replicated following a transient blood pressure decrease induced with PEEP (Nuttall 1987, unpublished observation).
}

TABLE I

SYSTEMIC VASCULAR PARAMETERS BEFORE AND AFTER NORMOVOLEMIC HEMODILUTION

\begin{tabular}{llllll}
\hline & $\begin{array}{l}\text { Hematocrit } \\
(\%) n=12\end{array}$ & $\begin{array}{l}\text { Blood pressure } \\
(\mathrm{mmHg}) n=13\end{array}$ & $\begin{array}{l}\mathrm{pCO}_{2}(\%) \\
n=14\end{array}$ & $\begin{array}{l}\mathrm{pO}_{2}(\%) \\
n=14\end{array}$ & $\begin{array}{l}\mathrm{pH} \\
n=14\end{array}$ \\
\hline $\begin{array}{l}\text { Before } \\
\text { Hemodilution } \\
(\text { mean } \pm \text { S.D.) }\end{array}$ & $41.8 \pm 2.8$ & $41.5 \pm 8.5$ & $3.96 \pm 0.85$ & $15.26 \pm 2.56$ & $7.49 \pm 0.10$ \\
$\begin{array}{l}\text { After } \\
\text { Hemodilution } \\
\text { (mean } \pm \text { S.D.) }\end{array}$ & $20.1 \pm 3.6$ & $41.8 \pm 7.6$ & $4.85 \pm 0.94$ & $14.43 \pm 2.28$ & $7.46 \pm 0.14$ \\
\hline
\end{tabular}



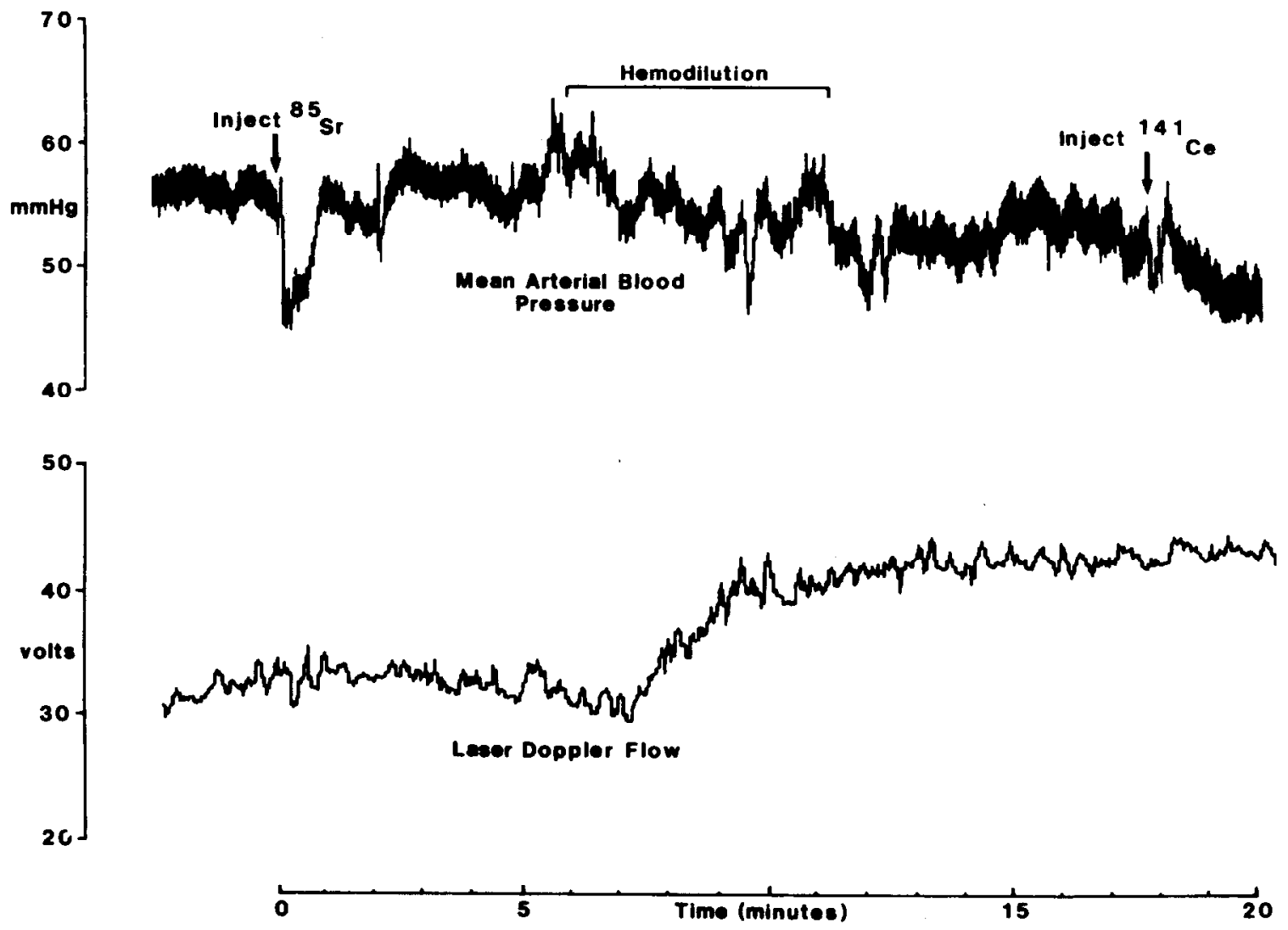

Fig. 1. Effect of normovolemic hemodilution on systemic blood pressure and laser Doppler measured cochlear blood flow in one guinea pig. At time $0 \mathrm{~s}$ the initial cochlear flow is measured by injection of ${ }^{85} \mathrm{Sr}$ microspheres. The time of hemodilution, with $5 \mathrm{cc}$ of Dextran 75, is labeled on the blood pressure graph. There is relatively little change in blood pressure but a large increase in laser Doppler measured cochlear blood flow. ${ }^{141} \mathrm{Ce}$ labeled microspheres are then injected to measure the hemodilution increased blood flow.

TABLE II

ORGAN BLOOD FLOW DETERMINED BY RADIOACTIVE MICROSPHERE TRAPPING AND LASER DOPPLER FLOWMETRY BEFORE AND AFTER NORMOVOLEMIC HEMODILUTION

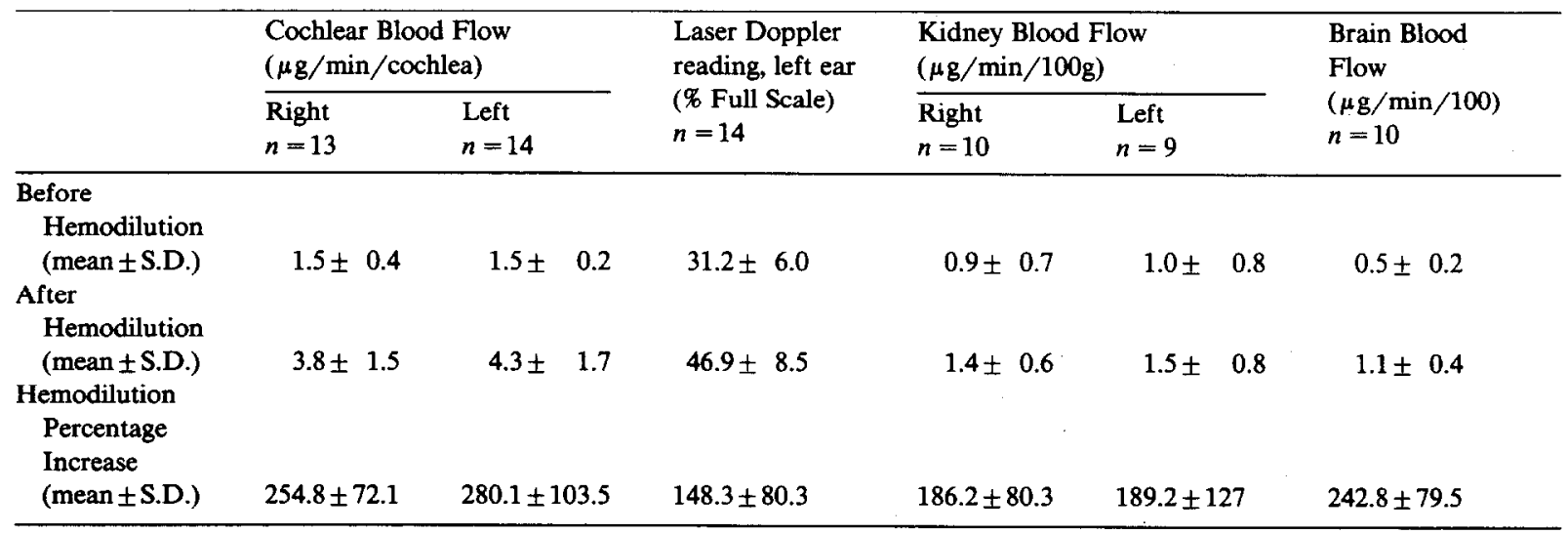



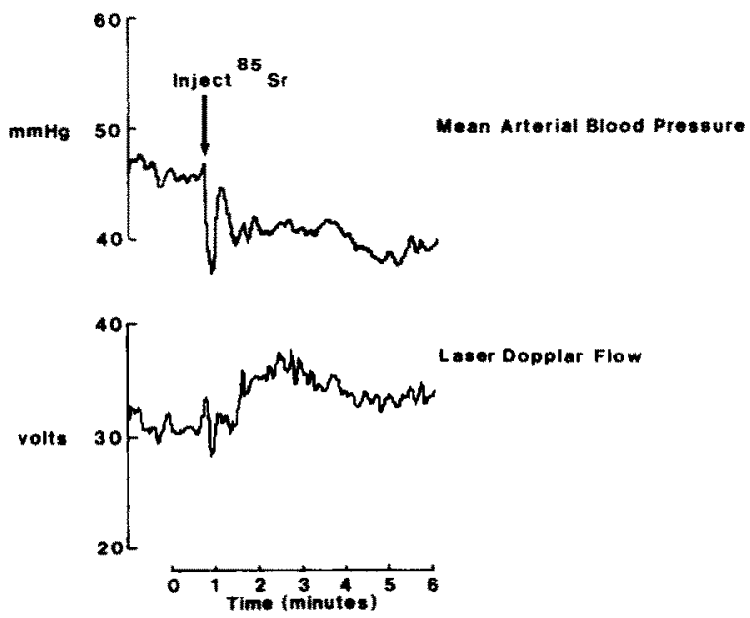

Fig. 2. An example, from one guinea pig, of the transient changes seen in the laser Doppler measured cochlear blood flow following microsphere injection. After an initial transient change related to the acute blood pressure change caused by microsphere injection, there is a slow rise in flow (beginning at time $2 \mathrm{~min}$ in the Figure) that is not simultaneously related to the blood pressure.

In Table 2 the measured blood flow increase in the cochleas (determined by microspheres) can be compared to the measured flow increase by laser Doppler flowmetry. Clearly the increase measured by laser Doppler flowmetry is significantly less than that given by microspheres $(P<0.0005$ by paired two-tail $t$-test).

The relationship of the increased flow, measured by microspheres, to that measured by laser Doppler flowmetry for each individual guinea pig is given in Fig. 3. The means and standard deviations of the bivariate data are given as well as a linear regression line fit to the data. Only a very low correlation was found between the laser Doppler measured blood flow increases and those simultaneously determined by the microsphere method. The possible reasons for the lack of correlation are given below.

\section{Discussion}

The first objective of this study was to quantitatively demonstrate the actual cochlear blood flow increase which is expected to occur as a result of hemodilution (Hultcrantz and Nuttall, 1987). In order to measure the flow, it was necessary to use a quantitative technique suitable for the cochlea.
The microsphere method is appropriate for this purpose. Hemodilution from an intravenous administration of $5 \mathrm{cc}$ of Dextran 75 solution reduced the systemic hematocrit to about $20 \%$. As a result of the hemodilution the microsphere-measured cochlear blood flow increased by approximately $250 \%$.

Anesthesia and hemodilution may cause the small variations of physiological parameters. These variations may lead to variability in the flow but are not expected to have a significant influence on the general observation of greatly increased cochlear blood flow. In this study, which tests the influence of hemodilution, it is necessary to ensure that conditions do not change during the experiment, thus shortening the time of the experiment was important. Hemodilution was accomplished over a 5 -min period by the relatively fast injection of dextran. The volume injected per minute, however, was only $1-2 \%$ of the cardiac output and the equal volume simultaneously removed from the left ventrical resulted in little net change in blood pressure.

Arturson and Thorén (1983) have shown that hemodilution can result in an increase in systemic oxygen transport capacity, because the velocity of blood increases at a faster rate than the decline in

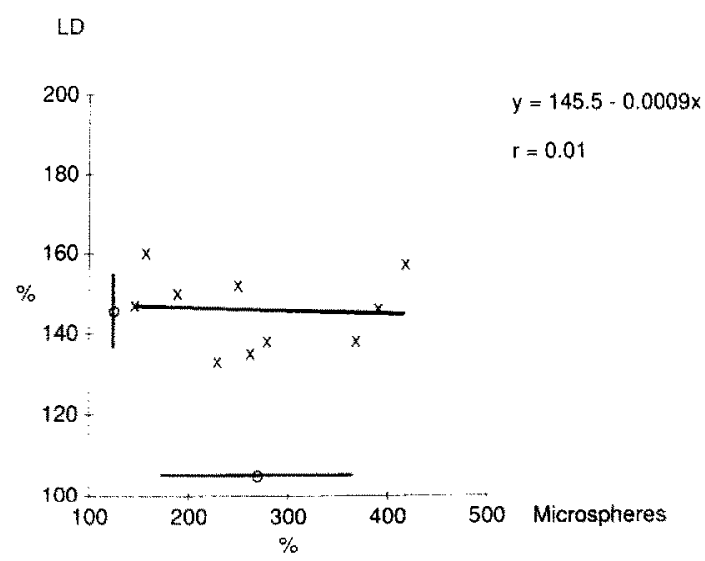

Fig. 3. Laser Doppler flowmeter measurements of change in left cochlear blood flow compared to microsphere indicator measurements of left cochlear flow. Data for ten individual guinea pigs are given following systemic hemodilution. The means $(0)$ and \pm 1 S.D. bars of the bivariate data are given near the axes. $A$ linear regression line, described by the equation is included and a correlation coefficient indicates poor correlation. 
oxygen carrying capacity due to the loss of hemoglobin. In an animal at rest, where autoregulatory systems are not activated, the blood flow increase is a purely rheological phenomenon resulting from non-linear blood viscosity changes. Since the critical low hematocrit is below $20 \%$, the dilution accomplished in this study is not expected to compromise metabolism; the blood gas measurements, before and after dilution, indicate a stable general physiological condition. Evidence that the blood flow increase is purely rheological is given by the comparison of the various organs in Table 2. The brain and each cochlea received approximately the same flow increase. Kidney blood flow increase (although symmetrical) was significantly less than the other organs. This may be related to function in the kidneys, which excrete the Dextran 75 solution.

Under the assumption that local vasodilitation or vascular recruitment does not occur (i.e., that vascular volume is constant), the entire flow increase measured by microsphere entrapment is due to an increase in the velocity of the blood. The laser Doppler flowmeter output, in contrast, is proportional to both the average velocity of blood cells perfusing a measured tissue volume and the total number of moving blood cells in the volume (Bonner et al., 1981; Nilsson et al., 1980). Thus, the reduction of hematocrit by one-half could be expected to result in a laser Doppler indication of cochlear blood flow about one-half of that recorded by microspheres. Table 3 shows that the laser Doppler flow is about 55\% of the microsphere flow.

The predicted result of a lower laser Doppler indication of blood flow during hemodilution stands in contrast to the apparent lack of correlation between laser Doppler and microsphere measurements when taken on an individual animal basis (Fig. 3). One reason for this might have been poor precision in the microsphere method for determining flow in a small organ. Buckberg et al. (1971) have shown that the small numbers of microspheres trapped in an organ (approximately 200 for each cochlea in the present study) will place the measurement precision well in excess of $25 \%$.

The accuracy of the cochlear blood flow measurements by microspheres can, however, be as-

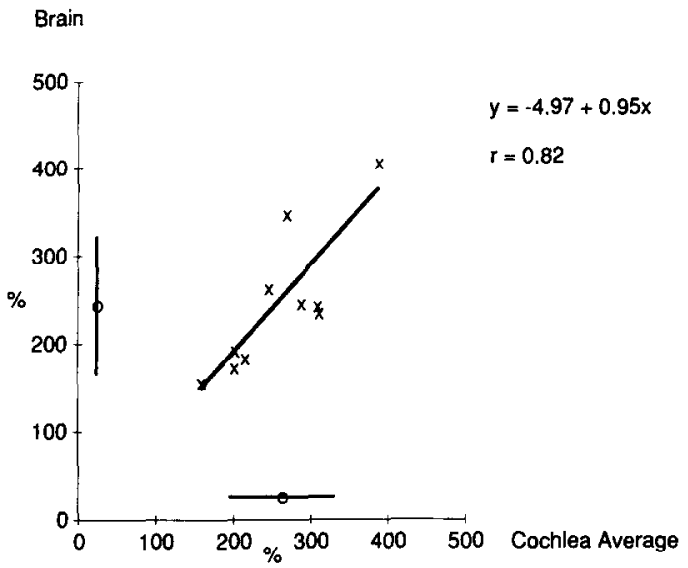

Fig. 4. A comparison of the increase in right brain hemisphere blood flow to the averaged left and right cochlear blood flow following systemic hemodilution. A regression line and correlation coefficient are given. The bars near the axis indicate +1 s.d. and the mean (0) of the bivariate data.

sessed by a comparison to brain flow. The brain receives a much greater proportion of the cardiac output and thus, a much greater number of microspheres are trapped in the measured tissue volume. These larger numbers greatly improve the precision of the brain blood flow measurement for each animal. Fig. 4 shows that microsphere-measured cochlear blood flow (right and left averaged) and right side brain blood flow are well correlated $(r=0.82)$. Therefore, the indications of flow change in the cochlea given by laser Doppler flowmetry may be subject to some error or variability in conditions of altered hematocrit.

There is evidence, from studies of local (capillary) hematocrit, that this parameter changes in a complex way among different capillaries and furthermore, that the capillary hematocrit does not change in proportion to the systemic hematocrit (Schmid-Schönbein and Rieger, 1981; Sarelius and Duling, 1982; Mirhashemi et al., 1987). Microrheological phenomena thus, could play a role in variability of laser Doppler measures of capillary perfusion. However, currently there is no clear rationale to account for the poor correlation between the two measures.

Angelborg and Larsen (1985) found that chinchillas breathing a $\mathrm{CO}_{2}$ mixture showed no increase of cochlear blood flow measured with the laser Doppler method, although the microsphere 
method showed a significant increase for the same conditions. When guinea pigs were used in the same protocol (Angelborg and Larsen, 1985), a measurable effect was found with the laser Doppler method. These results, and those of the current investigation, suggest that special care must be taken in the interpretation of the flowmeter measurements not only with the hemodilution protocol but also in the interpretation of the results using differing animal models.

It is clear that hemodilution increases cochlear blood flow in the guinea pig. The microsphere measurements of flow in the current study show a dramatically increased circulation which is greater than our previous determinations using laser Doppler flowmetry. The laser Doppler flowmeter on the average will underestimate the actual flow increase in hemodilution. This verification (provided by the microsphere indicator method) of the improved circulation supports the use of normovolemic hemodilution as a clinical procedure.

\section{Acknowledgements}

This work was supported by Public Health Service NIH Program Project (NS-05785) and NIH individual Grant (NS-11731) and Swedish Medical Research Council (MFR-04782). The authors wish to thank J. Nadine Brown, Michelle Griffiths and Birgitta Janson for technical support. They also acknowledge the gift of fentanyl used in the parts of this study done in the U.S.A. from Janssen Pharmaceutica, Inc. and the use of a periflux laser Doppler flowmeter in Sweden loaned by Perimed, AB.

\section{References}

Angelborg, C., Hultcrantz, E. and Agerup, B. (1977) The cochlear blood flow. Acta Otolaryngol. 83, 92-97.

Angelborg, C. and Larsen, H.C. (1985) Induced Changes of Inner Ear Blood Flow. Abst. 22nd Workshop on Inner Ear Biology, Würzburg.

Angelborg, C., Larsen, H.C. and Slepecky, N. (1985) Regional cochlear blood flow studies by observation of microspheres in serial sections. Ann. Oto. Rhino. Laryngol. 94, 181-185.

Arturson, G. and Thorén, L. (1983) Fluid therapy in shock. World J. Surg. 7, 573-580.

Axelsson, A. (1968) The vascular anatomy of the cochlea in the guinea pig and man. Acta Otolaryngol. Suppl. 242, 54-102.
Axelsson, A., Angelborg, C. and Larsen, H.C. (1983) The microsphere surface technique for evaluation of cochlear vessels and circulation. Acta Otolaryngol. 95, 297-305.

Bill, A. and Linder, J. (1976) Sympathetic control of cerebral blood flow in acute arterial hypertension. Acta Physiol. Scand. 96, 114-121.

Bonner, R.F., Clem, T.R., Bowen, P.D. and Bowman, R.L. (1981) Laser Doppler continuous real-time monitor of pulsatile and mean blood flow in tissue microcirculation. In: Scattering Techniques Applied to Supramolecular and Nonequilibrium Systems. Plenum Press, New York.

Brown, M.C., Smith, D.I. and Nuttall, A.L. (1983) The temperature dependency of neural and hair cell response evoked by high frequencies. J. Acoust. Soc. Am. 73, 1662-1670.

Brown, J.N., Thome, P.R., Nuttall, A.L. (1988) Blood Pressure in the Awake and Anesthetized Guinea Pig, (manuscript submitted).

Buckberg, G.D., Luck, J.C., Payne, D.B., Hoffman, J.I.E., Archie, J.D. and Fixer, D.E. (1971) Some sources of error in measuring regional blood flow with radioactive microspheres. J. Appl. Phys. 31, 598-604.

Canlon, B. and Schacht, J. (1983) Acoustic stimulation alters deoxyglucose uptake in the mouse cochlea and inferior colliculus. Hear. Res. 10, 217-226.

Costa, O. and Branemark, P.I. (1970) Vital microscopic evaluation of the microvessels of the cochlea. Adv. Microcirc. 3, 96-107.

Goodwin, P.C., Miller, J.M., Dengerink, H.A., Wright, J.W. and Axelsson, A. (1984) The laser Doppler. Acta Otolaryngol. 98, 403-412.

Hawkins, J.E., Jr. (1971) The role of vasoconstriction in noiseinduced hearing loss. Ann. Otol. 80, 903-913.

Hawkins, J.E., Jr., Johnsson, L.-G. and Preston, R.E. (1972) Symposium on basic ear research. Cochlear microvasculature in normal and damaged ears. Laryngoscope 82, 1091-1104.

Hultcrantz, E. (1979) The effect of noise on cochlear blood flow in the conscious rabbit. Acta Physiol. Scand. 106, 29-37.

Hultcrantz, E. and Angelborg, C. (1978) Cochlear blood circulation studies with microspheres. Oto-Rhino-Laryngol. 40, 65-76.

Hultcrantz, E., Linder, J. and Angelborg, C. (1977) Sympathetic effects on cochlear blood flow at different blood pressure levels. INSERM 68, 271-278.

Hultcrantz, E., Nuttall, A.L., Scheibe, F. and Miller, J.M. (1985) The effect of hemodilution by dextran on the cochlear blood flow. Proc. XIII World Congr. Otorhinolaryngol., Miami Beach, Florida, May, 1985. p. 167.

Hultcrantz, E. and Nuttall, A.L. (1987) Effect of hemodilution on cochlear blood flow measured by laser Doppler flowmetry. Am. J. Otolaryngol. 8, 16-22.

Larsen, H.-C., Angelborg, C. and Slepecky, B. (1984) Determination of the regional cochlear blood flow in the rat using non-radioactive microspheres and serially sectioned cochleas. Hear Res. 16, 127-132.

Lawrence, M. (1970) Circulation in the capillaries of the basilar membrane. Laryngoscope 80, 1364-1375. 
Lawrence, M. and Nuttall, A.L. (1972) Oxygen availability in tunnel of Corti measured by microelectrode. J. Acoust. Soc. Am. 52, 566-573.

Maass, B., and Kellner, J. (1984) Hydrogen clearance and cochlear microcirculation at different levels of blood pressure. Arch. Otorhinolaryngol. 240, 295-310.

Maass, B., Baumgartl, H., and Lubbers, D.W. (1976) Lokale $\mathrm{pO}_{2}$ und $\mathrm{pH}_{2}$ Messungen mit Nadelelektroden zum Studium der Saurstoffuersorgung und Mikrozirkulation des Innenohres. Arch. Otorhinolaryngol. 214, 109-124.

Miller, J.M., Goodwin, P.C. and Marks, N.J. (1984) Inner ear blood flow measured with a laser Doppler system. Arch. Otolaryngol. 110, 305-308.

Miller, J.M., Marks, N.J. and Goodwin, P.C. (1983) Laser Doppler measurements of cochlear blood flow. Hear. Res. 11, 385-394.

Mirhashemi, S., Messmer, K. and Intaglietta, M. (1987) Microvascular response of skeletal muscle and subcutaneous connective tissue to normovolemic hemodilution. Microcirculatory Society 34th Conf., Washington, DC, March, 1987. Abstract.

Misrahy, G.A., Hildreth, K.M., Shinabarger, E.W., Clark, L.C. and Rice, E.A. (1958) Endolymphatic oxygen tension in the cochlea of the guinea pig. J. Acoust. Soc. Am. 30, 247-250.

Morimitsu, T. (1960) Observations of the cochlear blood circulation in guinea pigs by impedance plethysmography. Otologia. Fukuoka 6, 437-457.

Nilsson, G.E., Tenland, T. and Oberg, P.A. (1980) A new instrument for continuous measurement of tissue blood flow by light beating spectroscopy. IEEE Trans. Biomed. Eng. BME-27(1); 12-19.

Nuttall, A.L. (1987) Techniques for the observation and measurement of red blood cell velocity in vessels of the guinea pig cochlea. Hear. Res. 27, 111-119.

Nuttall, A.L., Hultcrantz, E., Larsen, H.C. and Angelborg, C. (1987) Simultaneous laser Doppler and radioactive microsphere measurements of cochlear blood flow change during hemodilution. Abstr. Assoc. Res. Otolaryngol. Clearwater Beach, FL. February, 1987, p. 244.

Perlman, H.B. and Kimura, R.S. (1955) Observations of the living blood vessels of the cochlea. Ann. Otol. 64,
$1176-1192$.

Prazma, J., Vance, S.G. and Rodgers, G. (1984) Measurement of cochlear blood flow: New technique. Hear. Res. 14, 21-28.

Ross, M.D. (1971) Fluorescence and electron microscopic observations of the geneal visceral, efferent innervation of the inner ear. Acta Otolaryngol. Suppl. 286, 1-18.

Ryan, A.F., Woolf, N.K., and Sharp, F. (1984) Deoxyglucose uptake patterns in the auditory pathway: Metabolic response to sound stimulation in the adult and neonate. Abstr. Assoc. Res. Otolaryngol., St. Petersburg Beach, FL, $7,143$.

Sarelius, I.H. and Duling, B.R. (1982) Direct measurement of microvessel hematocrit, red cell flux, velocity and transit time. Am. J. Physiol. 243, H1018-H1026.

Schneider, E.A. (1974) A contribution to the physiology of the perilymph. Part I. The origin of perilymph. Ann. Otol. Rhinol. Laryngol. 83, 76-83.

Schmid-Schönbein, H. and Rieger, H. (1981) Why hemodilution in low flow states? Biblthca haemat. No. 47, 99-121.

Slepecky, N., Larsen, H.-C. and Angelborg, C. (1984) Computerized reconstruction of regional blood flow in the rodent cochlea. Hear. Res. 15, 95-101.

Slepecky, N., Angelborg, C. and Larsen, H.-C. (1987) Regional blood flow patterns along the rodent cochlea. Acta Otolaryngol. (Stockh.) 103, 176-181.

Spoendlin, H. (1976) Anatomical changes following various noise exposures. In: D. Henderson, K.P. Hamernick, D.S. Dosanjh and J.H. Mills (Eds.), Effects of Noise on Hearing, Raven Press, New York, pp. 69-87.

Suga, F. and Snow, J.B. (1969a) Adrenergic control of cochlear blood flow. Ann. Otol. Rhinol. Laryngol. 78, 358-374.

Suga, F. and Snow, J.B. (1969b) Cholinergic control of cochlear blood flow. Ann. Otol. Rhinol. Laryngol. 78, 1081-1090.

Vertes, D. and Axelsson, A. (1979) Methodological aspects of some inner ear vascular techniques. Acta Otolaryngol. 88, 328-334.

Weille, F.L., Gargano, S.R., Pfister, R., Martinez, D. and Irwin, J.W. (1954) Circulation of the spiral ligament and stria vascularis of living guinea pig. Arch. Otolaryngol. 59, 731-738. 